\title{
OS 20 ANOS DA LEI DE DIRETRIZES E BASES E A EDUCAÇÃO ESPECIAL: CONSIDERAÇÕES E REFLEXÕES
}

\author{
LOS 20 AÑOS DE LA LEY DE DIRECTRICES Y BASES Y LA \\ EDUCACIÓN ESPECIAL: CONSIDERACIONES Y REFLEXIONES
}

\author{
20 YEARS OF THE LAW ON BRAZILIAN EDUCATION GUIDELINES \\ AND BASES AND SPECIAL EDUCATION: CONSIDERATIONS AND \\ REFLECTIONS
}

\author{
Relma Urel Carbone CARNEIRO ${ }^{1}$ \\ Maria Júlia Canazza DALL'ACQUA ${ }^{2}$ \\ Patricia Moralis CARAMORI ${ }^{3}$
}

RESUMO: O texto apresentado procura empreender uma reflexão sobre alguns aspectos relativos ao período de 20 anos de vigência da Lei de Diretrizes e Bases da Educação Nacional (LDBEN) no que diz respeito à educação especial. São feitas considerações acerca do processo que levou à formulação de um capítulo voltado para tanto. São também apresentadas três temáticas, duas delas consideradas como pontos de flexibilidade e a última como evidenciado um aspecto de maior conservadorismo. Na primeira modalidade são apresentados e problematizados pontos que dizem respeito às condições estruturais e instrumentais específicas, o planejamento, o projeto político pedagógico, a gestão e a formação dos professores, em suas diferentes possibilidades. Finalizando são apresentados elementos para reflexão acerca do que permanece sendo um desafio para que a escola possa oferecer uma educação para todos.

PALAVRAS-CHAVE: Educação especial. Política educacional. Legislação.

RESUMEN: El texto presentado busca emprender una reflexión sobre aspectos relativos al período de 20 años efectivo de la Ley de Directrices y Bases de la Educación Nacional (LDBEN) al que dice respeto a la educación especial. Hay consideraciones sobre el proceso que llevó a la formulación de un capítulo sobre ella. También son presentadas tres temáticas, dos de ellas consideradas como puntos de flexibilidad y la última como un aspecto de mayor conservadorismo. En la primera modalidad son presentados y problematizados puntos que dicen respeto a las condiciones estructurales e instrumentales específicas, la planificación, el proyecto político pedagógico, la gestión y la formación de profesores, en sus diferentes posibilidades. Finalizando, son presentados elementos para reflexión sobre lo que

\footnotetext{
${ }^{1}$ Universidade Estadual Paulista (Unesp), Araraquara - SP - Brasil. Professora Assistente Doutora do Departamento de Psicologia da Educação. E-mail: relmaurel@ fclar.unesp.br.

${ }^{2}$ Universidade Estadual Paulista (Unesp), Araraquara - SP - Brasil. Professora Doutora aposentada do Departamento de Psicologia da Educação. E-mail: juliacandal@gmail.com.

${ }^{3}$ Universidade Federal de São Carlos (UFSCar), São Carlos - SP, Brasil. Pós-doutoranda em Educação Especial pelo Programa de Pós-graduação em Educação Especial. E-mail: p.caramori@uol.com.br.
}

RIAEE - Revista Ibero-Americana de Estudos em Educação, Araraquara, v. 13, n. 1, p. 190-206, jan./mar., 2018. 
permanece siendo un desafío para que la escuela pueda ofrecer una educación para todos.

PALABRAS-CLAVE: Educación especial. Política educacional. Legislación.

ABSTRACT: The text tries to present some reflections on certain aspects regarding special education related to the 20-year period of validity of the Law on Brazilian Education Guidelines and Bases (LDBEN). It presents some considerations on the process that led to the formulation of a chapter about the argument. Three themes are presented as well. Two of them are considered as flexibility points and the third one highlights a more conservative aspect. The first mode discusses some points related to specific structural and instrumental conditions, planning, political-pedagogical project, teachers management and training and their multiple possibilities. Finally, it proposes some elements for reflection on the challenges that remain for the school to offer education for everyone.

KEYWORDS: Special Education. Educational Politics. Legislation.

\section{Introdução}

A Lei de Diretrizes e Bases da Educação Nacional (doravante LDBEN), Lei $n^{\circ}$ 9.394/96 (BRASIL, 1996), estabelece os princípios gerais para todo o sistema educacional do País. Traz modificações importantes para a educação brasileira, em comparação à LDBEN anterior, Lei $n^{\circ}$ 5.692/71 (BRASIL, 1971). Antes de enfocar especificamente a temática da Educação Especial e sua delimitação no contexto geral, faz-se importante resgatar a trajetória percorrida enquanto essa lei foi estruturada até ser aprovada e, finalmente, promulgada como o conjunto de normas e regras que regem o sistema educacional do País.

Desde a Constituição Brasileira de 1988 (BRASIL, 1988), a Lei nº 9.394 (BRASIL, 1996) levou oito anos sendo discutida antes de ser sancionada.

A proposta foi debatida e reformulada com a inclusão de um capítulo sobre a Educação Especial e não mais apenas um artigo, o que já é considerado um avanço em relação à lei vigente na ocasião. Vale ressaltar que, salvo algumas alterações terminológicas, até sua redação final e aprovação como Lei n 9.394, em 1996, o texto manteve-se praticamente o mesmo.

Assim, em maio de 1993, o então Senador Darcy Ribeiro, que veio a dar nome à nova LDBEN, deu entrada a um Projeto de Lei, em caráter de urgência, bem diverso do 
que já tramitava na Câmara dos Deputados. Neste projeto, a Educação Especial voltou à condição de artigo localizado no capítulo referente aos diferentes níveis de ensino.

Após um parecer da Coordenadoria Nacional para a Integração da Pessoa com Deficiência (CORDE) com ponderações acerca da Educação Especial e outros pareceres de educadores estudiosos de outras áreas da Educação, o Senador Darcy Ribeiro apresentou uma nova proposta parecida na estrutura, porém diferente no conteúdo, a qual, finalmente, foi aprovada e promulgada em 20 de dezembro de 1996: a Lei $\mathrm{n}^{\circ}$ 9.394/96 (BRASIL, 1996).

Ela conta com 92 artigos distribuídos no conjunto de nove títulos. No Título V, denominado "Dos Níveis e das Modalidades de Educação e Ensino", há o Capítulo V que trata "Da Educação Especial", entendida como “[...] modalidade de educação escolar oferecida preferencialmente na rede regular de ensino, para educandos [...]" (BRASIL, 1996, p.43) que apresentam necessidades especiais.

No período de aprovação da LDBEN, Carvalho (1997) destaca que prevalecia no País o enfoque determinista, pois, em sua maioria, as pessoas na época denominadas com necessidades especiais não tinham outra opção além de preencher as vagas das instituições especializadas. Isso se dava pela insuficiência de oportunidades de acesso, ingresso e permanência nas escolas regulares.

Sobre as três leis de diretrizes e bases já existentes no País, a autora (CARVALHO, 1997) as classifica da seguinte forma:

a) Lei $\mathrm{n}^{\mathrm{o}}$ 4.024/61: sob a égide do nacional desenvolvimentismo que prevalecia no País, privilegia o homem de conhecimento abrangentes, generalista;

b) Lei $n^{\circ} 5.692 / 71$ : com a internacionalização da economia, tem o caráter de suprimento do mercado de trabalho, a profissionalização;

c) Lei $n^{\circ}$ 9.394/96: característica de flexibilidade, abertura e algumas inovações, porém, com alguns pontos conservadores.

Alguns pontos de flexibilidade e de conservadorismo são elencados e, segundo essa lógica de Carvalho (1997), optou-se por selecionar, para a discussão, três temáticas, sendo as duas primeiras caracterizadas pela flexibilidade e a terceira identificada como conservadora: 
- incumbência dos sistemas de ensino em elaborar seus próprios Projetos Político-Pedagógicos e valorização dos profissionais da educação;

- multiplicidade de alternativas para formação do professor e incentivo à Educação a Distância;

- dicotomia entre regular e especial e correlação biunívoca entre as necessidades especiais e a Educação Especial.

Cada uma dessas temáticas será abordada de forma mais elaborada a seguir.

\section{Projeto Político-Pedagógico}

Considerando o aspecto "Incumbência dos estabelecimentos de ensino em elaborar suas próprias propostas pedagógicas", é salutar observar que esta temática aparece no início do texto da Lei, já no Título II, que trata "Dos princípios e fins da educação nacional” no item VIII do artigo $3^{\circ}$ que, dentre outros princípios prevê “[...] gestão democrática do ensino público, na forma desta Lei e da legislação dos sistemas de ensino" (BRASIL, 1996). Este princípio apresenta-se como imprescindível em um contexto educacional que busca um modelo de educação que seja extensivo a todos, entendendo o termo "todos" como absoluto, ou seja, sem nenhuma forma de exclusão. Para os alunos Público-alvo da Educação Especial (doravante PAEE), que historicamente ficaram alijados do sistema comum de ensino, a participação no processo de escolarização comum pressupõe modificações em toda estrutura escolar, o que só será possível, a nosso ver, a partir de um modelo de gestão que seja democrático, modelo esse que tem como uma de suas premissas básicas um regime em que não existam desigualdades e/ou privilégios de grupos. No entanto, essa forma de gestão não é uma realidade em nosso contexto que, ao longo do tempo, incorporou um modelo administrativo empresarial, reprodutor das relações sociais capitalistas, ignorando um aspecto primordial que diferencia a escola de qualquer outra organização.

Um dos elementos necessários para escolarização de alunos PAEE em particular, e de todos os outros em geral, nos ambientes comuns de ensino, é a oferta de condições estruturais e instrumentais específicas de acordo com a característica de cada um. O planejamento para o atendimento a todas as condições provenientes das especificidades é tarefa da gestão escolar, que deve atuar de forma coletiva com todos os envolvidos no processo educacional de forma a garantir a satisfação das necessidades. 
Esse planejamento e sua elaboração de forma coletiva também estão previstos na LDBEN (BRASIL, 1996) que, no Título IV, que trata "Da Organização da Educação Nacional", prevê em seu artigo 12 que "Os estabelecimentos de ensino, respeitadas as normas comuns e as do seu sistema de ensino, terão a incumbência de [entre outros] elaborar e executar sua proposta pedagógica [...]". No artigo 13, a referida Lei prevê que “Os docentes incumbir-se-ão de [...]" participar dessa elaboração.

A seriedade e complexidade desta tarefa indicam a necessidade da participação coletiva apontada pela Lei (BRASIL, 1996). Nos dizeres de Marçal (2001, p. 34),

$\mathrm{O}$ projeto pedagógico é, portanto, o instrumento que explicita a intencionalidade da escola como instituição, indicando seu rumo e sua direção. Ao ser construído coletivamente, permite que os diversos atores expressem suas concepções (de sociedade, escola, relação ensino-aprendizagem, avaliação etc.) e seus pontos de vista sobre o cotidiano escolar, observando-se tanto o que a escola já é quanto o que ela poderá vir a ser, com base na definição de objetivos comuns das ações compartilhadas por seus atores.

Neste trecho, o autor apresenta dois aspectos fundamentais que são a intencionalidade e a responsabilidade de todos os envolvidos, que na implementação prática do projeto pedagógico na escola consolida o caráter democrático da gestão, uma vez que na realização do proposto todos os envolvidos terão oportunidade de vivenciar o trabalho do qual são corresponsáveis. Desta forma, a avaliação dos problemas apresentados também fica mais fácil, uma vez que todos respondem pelo projeto. As melhorias e avanços também são méritos de todos, e assim a equipe, a escola e principalmente os alunos, razão primeira da existência da escola, são beneficiados.

Vinte anos depois da promulgação da LDBEN (BRASIL, 1996), o que temos vivenciado no cotidiano escolar brasileiro é uma imensa dificuldade em incorporar em sua prática uma gestão coletiva e democrática que se traduza na elaboração de suas propostas pedagógicas, em especial no que concerne ao reconhecimento, valorização e operacionalização da atuação com grupos específicos, como os alunos PAEE, que requerem ações tanto no sentido estrutural quanto pedagógico.

Em relação à "Valorização dos profissionais da educação", no Título VI, que trata "Dos Profissionais da Educação", temos: 
Art. 67. Os sistemas de ensino promoverão a valorização dos profissionais da educação, assegurando-lhes, inclusive nos termos dos estatutos e dos planos de carreira do magistério público: títulos;

I - ingresso exclusivamente por concurso público de provas e

II - aperfeiçoamento profissional continuado, inclusive com licenciamento periódico remunerado para esse fim;

III - piso salarial profissional;

IV - progressão funcional baseada na titulação ou habilitação, e na avaliação do desempenho;

V - período reservado a estudos, planejamento e avaliação, incluído na carga de trabalho;

VI - condições adequadas de trabalho. (BRASIL, 1996, p. 48).

Este artigo prevê que é responsabilidade dos sistemas de ensino promover a valorização dos profissionais da Educação e coloca alguns itens como garantidores desta valorização. No entanto, a LDBEN não apresenta mecanismos de cobrança e tampouco de fiscalização efetiva que garantam tal cumprimento. Assim, passados vinte anos, observamos que a valorização pretendida não foi alcançada em todo território nacional. O ingresso não acontece exclusivamente por "concurso público" em todos os sistemas de ensino; a "formação continuada remunerada", portanto, dentro da carga horária de trabalho, é quase inexistente, contrariando teorias contemporâneas sobre formação docente que advogam sobre uma formação em serviço que aconteça na própria escola, usando o fazer docente como objeto de reflexão e capacitação, conforme apontam Nóvoa (1995), Mizukami et al. (2002), Gomes (2009), Rodrigues (2011) e Tardif (2012), entre muitos outros. O "piso salarial” não é respeitado e não reflete em valores o que poderíamos chamar de uma remuneração que valoriza o profissional da Educação, muito pelo contrário, é insuficiente para manutenção de uma família, o que obriga o profissional a trabalhar dois ou três períodos, muitas vezes em escolas diferentes e/ou fazendo outros trabalhos como complementação de renda.

A "progressão funcional baseada na avaliação do desempenho", por ser medida a partir de avaliações externas do desempenho dos alunos, muitas vezes se configura como prejudicial a um modelo de escola que considera as diferenças, o que leva muitas escolas a excluírem os alunos PAEE deste processo por entenderem que suas performances podem ser negativas à avaliação da escola como um todo. $\mathrm{O}$ "período reservado a estudos, planejamento e avaliação, incluído na carga de trabalho" tem sido cada vez mais instituído, embora não em todos os sistemas de ensino, na forma de Hora de Trabalho Pedagógico Coletivo (HTPC) e Hora de Trabalho Pedagógico Individual

RIAEE - Revista Ibero-Americana de Estudos em Educação, Araraquara, v. 13, n. 1, p. 190-206, jan./mar., 2018. 
(HTPI), no entanto, a otimização deste tempo requer ações planejadas ainda incipientes na maioria de nossas escolas, que, por falta de uma tradição na ação reflexiva e proativa, acabam subutilizando este tempo fundamental para organização do fazer docente.

O último item considerado no artigo, "condições adequadas de trabalho", talvez seja o mais complexo, uma vez que de forma indireta abrange também aspectos dos outros itens. Para além dos já mencionados, é comum a queixa de salas de aula muito numerosas, falta de infraestrutura básica, de recursos materiais e humanos, de apoio técnico, enfim, um sem número de fatores que atestam a inadequação das condições de trabalho em muitas escolas no Brasil. Reconhecemos que esta análise, um tanto pessimista, não reflete a totalidade de nossa realidade, porém, não podemos deixar de considerar que se todos os itens previstos no artigo 67 não são comuns a todas as escolas, ainda estamos distantes de transformar em prática a letra da LDBEN.

\section{Formação de professores}

O percurso da legislação sobre a formação de professores a partir da LDBEN mostra altos e baixos até os dias de hoje. Primeiro, a LDBEN instituiu a exigência de nível superior para os professores da Educação Básica e estipulou um prazo de dez anos para que todos os professores efetivos se adequassem à nova legislação. Além disso, propôs mudanças para as instituições e para os cursos de formação.

O ano seguinte ao da promulgação da LDBEN, 1997, marcou o início de uma disputa dos Institutos Superiores de Educação e das Escolas Normais Superiores contra as Faculdades de Pedagogia, pois os professores de $1^{\mathrm{a}}$ à $4^{\mathrm{a}}$ série, designação adotada para os anos iniciais do Ensino Fundamental I, eram formados sem diretrizes claras.

Em 2001, a Resolução CNE/CEB No 2 (BRASIL, 2001), que Institui Diretrizes Nacionais para a Educação Especial na Educação Básica, estabeleceu que os professores deveriam ser formados em nível médio ou superior, porém necessitariam comprovar conteúdos sobre a temática da Educação Especial em sua formação. Esses conteúdos permitiriam perceber as necessidades educacionais especiais dos alunos, bem como valorizar a educação inclusiva no ambiente escolar. Isso significa que professores do ensino regular com algum conhecimento sobre Educação Especial seriam capazes de valorizar a inclusão e trabalhar com os alunos PAEE.

Já para a atuação como professor de Educação Especial, cobrava-se a formação em cursos de Licenciatura em Educação Especial ou em uma de suas áreas. Essa

RIAEE - Revista Ibero-Americana de Estudos em Educação, Araraquara, v. 13, n. 1, p. 190-206, jan./mar., 2018. 
formação deveria se dar, preferencialmente, de modo concomitante e associado à Licenciatura para Educação Infantil ou para os anos iniciais do Ensino Fundamental, Pedagogia ou Curso Normal Superior. Também seria aceitável que essa formação fosse na pós-graduação.

No ano de 2002, a Resolução CNE/CP no 1 (BRASIL, 2002), que Institui Diretrizes Curriculares Nacionais para a Formação de Professores da Educação Básica, trouxe a indicação de que a formação docente deveria ser voltada para a atenção à diversidade, incluindo questões culturais, sociais, econômicas e as necessidades educacionais, sem qualquer menção à formação na modalidade a distância.

Em 2003 o Conselho Nacional de Educação emitiu resolução (BRASIL, 2003) e nota de esclarecimento reafirmando, após sete anos, a obrigatoriedade do diploma em nível superior para a docência na Educação Infantil e nas séries iniciais do Ensino Fundamental. No mesmo ano o Governo Federal implementou o Programa de Educação Inclusiva, incentivando a transformação dos sistemas de ensino em sistemas inclusivos. Esse programa propôs a formação de gestores e professores das escolas públicas brasileiras, por meio de replicadores, com o intuito de garantir o acesso de todos à escola e ao atendimento educacional especializado (AEE), direito de todos os alunos PAEE.

No ano de 2005, depois de nove anos de vigência da LDBEN, a Educação a Distância é regulamentada no Brasil com o Decreto no 5.622 (BRASIL, 2005). A partir de então muitos cursos, nos níveis de ensino Médio, Profissionalizante e Educação Superior, foram criados nessa modalidade.

Até esse momento a diretriz sobre formação de professores vinha do texto da LDBEN, não havendo outra lei, decreto, ou resolução que a alterasse. Somente em 2006 seriam apresentadas as Diretrizes Curriculares Nacionais para o Curso de Graduação em Pedagogia, Licenciatura, pela Resolução CNE/CP nº 01/2006 (BRASIL, 2006). A partir daí a formação de professores de Educação Especial passaria a ser realizada em nível de pós-graduação lato sensu, ficando a cargo da formação inicial, formar os professores para atuar na Educação Infantil, anos iniciais do Ensino Fundamental, Ensino Médio, na modalidade Normal e Educação de Jovens e Adultos (EJA), habilitando-os a demonstrar consciência da diversidade, respeitando as diferenças, incluindo as necessidades especiais dos alunos. Dessa forma, as diretrizes para o curso de Pedagogia referentes à formação docente para ensino de alunos PAEE matriculados em salas comuns teriam 
um caráter vago, limitando-se obrigatoriamente a uma disciplina no curso. Neste documento não há qualquer menção aos cursos de formação na modalidade a distância.

Em 2007 era apresentado o Plano de Desenvolvimento da Educação (PDE) (BRASIL, 2007), uma espécie de plano de ações para alcançar as metas do Plano Nacional de Educação (PNE) (BRASIL, 2001a). O documento trazia a ideia de superar a oposição entre Educação Regular e Especial e tinha como eixo de discussão a formação de professores de Educação Especial, a implantação das Salas de Recurso Multifuncional (SRM) e a acessibilidade.

Em 2010 o PNE era renovado com metas a serem cumpridas de 2011 a 2020 (BRASIL, 2010), abordando mais enfaticamente a questão da formação continuada para melhoria da qualidade da oferta de ensino, porém também incentivava o aumento da oferta de formação inicial, principalmente nas licenciaturas, como Matemática e Ciências, disciplinas específicas do Ensino Fundamental II. Além disso, cita a Implantação das SRM com o concomitante fomento da formação continuada de professores para o AEE. A modalidade de ensino a distância na Educação Superior é citada no documento como uma oportunidade de formação daqueles que vivem em lugares mais afastados e desprovidos de instituições de ensino, inviabilizando a formação.

Em 2014, um novo PNE era aprovado (Lei n 13.005/14) (BRASIL, 2014a), com vigência para os dez anos seguintes. Novas metas e objetivos foram traçados e a Meta 15 diz respeito à proposta de garantir uma política nacional de formação dos profissionais da Educação, tratada nos incisos I, II e III do caput do art. 61 da Lei ${ }^{\circ}$ 9.394/96 (BRASIL, 1996), LDBEN, assegurando que todos os professores da Educação Básica possuam formação específica de nível superior, obtida por meio de licenciatura na área de conhecimento em que atuam. O Censo Escolar 2013 aponta, 17 anos depois da homologação da LDBEN, que 74,8\% dos professores da Educação Básica têm formação em curso superior, e a Meta 15 do PNE pretende que 100\% dos professores tenham essa formação. Uma das 13 estratégias para se alcançar essa meta é o incentivo aos programas de iniciação à docência e de estágio existentes nas licenciaturas (BRASIL, 2014b).

Por último, a legislação mais recente sobre formação de professores é a Resolução CNE/CP 02/2015 (BRASIL, 2015) que reitera a formação de professores, inicial e continuada, para a Educação Básica, apenas habilitando-os para trabalhar com a Educação Infantil, os anos iniciais do Ensino Fundamental e o Ensino Médio, 
reafirmando suas modalidades, entre elas a Educação Especial. Um diferencial desse documento é a abordagem da segunda licenciatura para professores especialistas que ainda não possuem a formação em Pedagogia. No caso, a segunda licenciatura tem uma carga horária menor, caracterizando uma complementação pedagógica, mesmo que a legislação não a chame dessa maneira.

Esse foi o percurso da legislação brasileira no que diz respeito à formação de professores com mudanças significativas, porém que ainda indicam a necessidade de pesquisas mais profundas sobre seus impactos na realidade escolar e educacional das crianças e jovens do País, sejam eles PAEE ou não.

\section{Dicotomia entre Ensino Regular e Especial}

Sobre essa temática cabe uma revisão da trajetória da LDBEN (BRASIL, 1996). Para tanto, é preciso retroagir alguns anos e considerar as implicações da assinatura do pacto pelo desenvolvimento da "Educação para Todos" (DECLARAÇÃO, 1990), documento mundial do qual o Brasil também foi signatário e que teve reflexos importantes na definição dos contornos da, então, nova LDBEN (BRASIL, 1996).

Frente ao panorama de desigualdades educacionais e a necessidade de ampliação e garantia de acesso de todas as crianças e jovens à escolarização, era preciso uma ruptura com a escola tradicional. O ideal de uma escola para todos, indistintamente, começava a desenhar-se no horizonte, com base no respeito à diferença e na busca pela igualdade de oportunidades.

Tal prerrogativa lançava os alicerces de uma educação inclusiva, rompendo com o ideário da homogeneidade. Como trazer para dentro dessa escola, ou mesmo impedir a exclusão, daqueles considerados diferentes? Nesse sentido a LDBEN (BRASIL, 1996) propôs-se a estabelecer o acesso e a permanência com igualdade de condições, cujo texto e em seu Título III, que trata "Do Direito à Educação e o Dever de Educar", estabelece no artigo $4^{\circ}$ o dever do Estado quanto ao provimento obrigatório e gratuito da educação escolar. Contudo, era necessária uma ruptura com o modelo de escola tradicional, pois a universalização do acesso implicaria em alunos com uma diversidade maior de formas de aprender. Assim, a sua aprovação veio apresentar uma perspectiva de ruptura e de inflexão para enfrentamento das desigualdades. 
A Educação como direito de todos os alunos impõe a exigência não apenas de mais vagas, escolas, professores, mas, também, um fazer pedagógico que é desafiado pela diferença, pois o ideal de igualdade passa pelo reconhecimento da diferença.

Considerada um avanço, “[...] o fato de a nova LDB reservar um capítulo exclusivo para a educação especial parece relevante para uma área tão pouco contemplada, historicamente, no conjunto das políticas públicas brasileiras", tal como bem indicado em artigo de Ferreira (1998) que já procurava realizar, apenas dois anos após sua promulgação, uma análise acerca das implicações da referida lei. Definida como modalidade de educação escolar, estabeleceu o direito à educação pública para aqueles que, tradicionalmente, permaneciam excluídos ou eram alunos em escolas especializadas. Nesse sentido, com ampliação na possibilidade de acesso à escolarização de alunos na época denominados com necessidades educacionais especiais, ainda assim a inserção "[...] da educação especial nos debates da educação geral - até por ser uma área de presença relativamente recente no âmbito da educação escolar básica e por não se constituir em prioridade nas políticas educacionais [...]” (FERREIRA, 1988), mostrou-se ainda mais indefinida em função do lócus do AEE poder ser, preferencialmente, da rede regular de ensino.

Se, por um lado, o cenário restritivo sinaliza na direção de uma abertura importante para a Educação Especial junto à Educação Escolar, por outro, a dicotomia entre Ensino Regular e Especial evidencia o desafio de romper a estigmatização e a segregação, de forma a possibilitar uma presença mais ampliada no movimento de construção de uma escola para todos.

O princípio de inclusão parece ser o elemento responsável por promover " [...] mudanças que deveriam beneficiar grupos sociais historicamente empurrados $\mathrm{e}$ mantidos à margem da sociedade e dos direitos humanos [...]" (FERREIRA, 2015, p. 92). Dessa forma, a perspectiva de uma Educação Especial como modalidade de Educação Escolar parece ter sido um movimento promissor. Contudo, ao manter o apoio educacional especializado no Ensino Regular, mas, também, prever serviços especiais separados em virtude das condições específicas dos alunos, a lei minimiza o papel da escola e maximiza a relevância das características pessoais dos alunos, de forma a individualizar o critério de decisão no aluno, responsabilizando-o pelo tipo de escola a que tem direito. Tal argumento exime de atribuições as condições do sistema de ensino, que se preserva inalterado. Quem se adapta é o aluno, não a escola, tal como o modelo de integração. A dicotomia que se estabelece entre a Educação Regular e a 
Especial evidencia que, para os alunos considerados como aqueles que não necessitam de AEE, a Educação tem papel fundamental na formação. Para os demais, os limites inerentes ao próprio aprendiz cerceiam as possibilidades da Educação desempenhar seu papel, condicionando-a às necessidades especiais dos aprendizes.

A questão central aqui apresentada não se firma na defesa apenas da escola regular como espaço de escolarização de alunos PAEE. É possível e desejável haver alternativas. Contudo, ao propor uma educação denominada inclusiva, mas que coloca sobre a população alvo a responsabilidade pelo seu desempenho, a LDBEN abre a perspectiva para que a escola diferencie o papel da educação no curso da aprendizagem e desenvolvimento dos alunos. Tomando como referência Skrtic (2014), a legislação, ela própria, “[...] perpetua as injustiças que deveria eliminar, introduzindo e sustentando novas [...]”. (SKRTIC, 2014, p. 177).

Contudo, a despeito desse fato, não há como negar que o conceito de inclusão tornou-se um princípio orientador que, juntamente com a universalização do acesso à escolarização, cada vez mais cedo e ao longo de cada vez mais tempo, propiciou que se testemunhasse o surgimento de um conjunto de políticas favoráveis à permanência, em salas comuns, de alunos tradicionalmente considerados invisíveis ou inexistentes. Nessa linha de raciocínio faz-se importante analisar algumas alterações em dispositivos da LDBEN (BRASIL, 1996) ocorridas em 2013, quando a legislação original é modificada pela Lei $n^{\circ}$ 12.796/13 (BRASIL, 2013) para atender ao estabelecido pela Emenda Constitucional $\mathrm{n}^{\circ}$ 59, de 2009 (BRASIL, 2009), que ampliou a referida obrigatoriedade escolar para a faixa etária de 4 a 17 anos, tornando assim obrigatória a matrícula de crianças na Educação Infantil a partir de quatro anos e o AEE também já no início da mesma.

Até pouco tempo, o Brasil utilizava a taxa de atendimento de 7 a 14 anos, que equivalia ao Ensino Fundamental de oito anos. O elevado percentual de crianças e jovens nessa faixa etária na escola imprimiu a ideia de que o país teria universalizado o Ensino Fundamental. De lá para cá, porém, ocorreram duas mudanças importantes: o Ensino Fundamental passou a ser de nove anos (vai dos 6 aos 14 anos) e a Pré-Escola e o Ensino Médio tornaram-se obrigatórios. O texto constitucional aprovado em 2009 institui a obrigatoriedade da Educação Básica gratuita para todos com idade de 4 a 17 anos, com implementação pelas redes prevista até 2016. (BRASIL, 2012, p. 24-25).

Ampliar a obrigatoriedade e a universalização para além de estatísticas tímidas em relação às matrículas de alunos PAEE em escolas regulares que, segundo 
estimativas, no todo não ultrapassam 2\% (MENDES, 2006; DALL'ACQUA; VITALIANO, 2010), pode ser considerada uma meta e um legado da maior relevância, dado que essa inserção gradual, embora lenta, ainda assim mostra-se em expansão.

Especificamente no tocante à Educação Infantil que, a partir das alterações na LDBEN, passou a ocupar um espaço de singular importância, cabe destacar que, como enfatiza Mendes (2010, p. 50-51), “[...] predomina na atualidade uma ideologia de que todos os Programas de Educação Infantil devem estar preparados para se tornarem inclusivos [...]". Tal colocação reforça o argumento em favor das modificações introduzidas após a aprovação da Lei no 12.796/13 (BRASIL, 2013), visando alterar a incidência de matrículas concentradas no Ensino Fundamental como uma tendência majoritária.

Dessa forma, acrescido esse fato pelo aspecto de que embora a Educação Infantil seja uma etapa decisiva para o desenvolvimento e aprendizagem de crianças, os programas "[...] podem não atender padrões de alta qualidade e a consequência disso seria a colocação de crianças com dificuldades em programas de qualidade abaixo da adequada até mesmo para crianças com desenvolvimento típico [...]” (MENDES, 2010, p. 51). Assim sendo, percebe-se que apenas ampliar matrículas não significa, necessariamente, uma mudança de perspectiva, de fato.

Dando continuidade às alterações na LDBEN (BRASIL, 1996) a partir da Lei $n^{\circ}$ 12.796/13 (BRASIL, 2013), a redação que contemplava a terminologia "educandos portadores de necessidades especiais" foi substituída pela denominação "educandos com deficiência, transtornos globais do desenvolvimento e altas habilidades ou superdotação".

A partir da explicitação de que contingente são os que podem ser reconhecidos como PAEE, por conseguinte, pela legislação também prevê-se o AEE, segundo as condições específicas dos alunos. Dessa forma caracteriza-se “[...] espaço da sala de AEE como um espaço escolar de exclusão e estigmatização do/a aluno/a com deficiência institucionalizado pela política de educação especial [de tal sorte que] a política de inclusão dirige o foco de atenção novamente ao/à aluno/a, e não ao ambiente escolar e às barreiras ao acesso, à participação e à aprendizagem [...].” (FERREIRA, 2015, p. 95). Consolida-se, assim, o que Carvalho (1997) denominou, à época, como correlação biunívoca entre as necessidades especiais e a Educação Especial.

RIAEE - Revista Ibero-Americana de Estudos em Educação, Araraquara, v. 13, n. 1, p. 190-206, jan./mar., 2018. 


\section{Algumas considerações}

O exercício de análise proposto mostrou a complexidade de tal tarefa, uma vez que a abrangência e desdobramentos da LDBEN são inúmeros. Em relação aos aspectos referentes à Educação Especial apresentados, observa-se que a lei traz avanços, como o reconhecimento da área enquanto modalidade e a necessidade de um olhar voltado para suas especificidades, ao mesmo tempo em que consolida práticas excludentes de categorização e de responsabilização do indivíduo e não das barreiras impostas socialmente e aponta vários elementos fundamentais para as mudanças necessárias rumo à Educação de qualidade para todos, como a elaboração e efetivação do projeto pedagógico de forma autônoma, o estabelecimento de políticas sólidas e concretas de valorização dos profissionais da Educação e o investimento constante na formação como essencial no processo de transformação de um modelo excludente para um inclusivo. Nesses 20 anos, um balaço possível é que as políticas educacionais brasileiras precisam ser aprimoradas e incorporadas de forma equânime, transpondo a barreira do legal para o real.

\section{REFERÊNCIAS}

BUENO, J. G. S.; MELETTI, S. M. F. A Educação infantil e educação especial: uma análise dos indicadores educacionais brasileiros. Revista Contrapontos, Itajaí, v. 11, n.3, p.278-287, set./dez., 2011.

BRASIL. Presidência da República. Casa Civil. Subchefia para Assuntos Jurídicos. Lei $n^{\circ} 5.692 / 71$, de 11 de agosto de 1971. Fixa Diretrizes e Bases para o ensino de $1^{\circ}$ e $2^{\circ}$ graus, e dá outras providências. Brasília, DF. Disponível em:

<http://www.planalto.gov.br/ccivil_03/leis/L5692.htm>. Acesso em: 30 abr. 2016.

BRASIL. Constituição. Constituição da República Federativa do Brasil. Brasília, DF: Senado Federal: Centro Gráfico, 1988.

BRASIL. Ministério da Educação. Lei no 9.394/96. Lei de Diretrizes e Bases da Educação Nacional. Brasília: MEC, 1996.

BRASIL. Presidência da República. Casa Civil. Subchefia para Assuntos Jurídicos. Lei $\mathbf{n}^{\circ}$ 10.172, de 9 de janeiro de 2001. Aprova o Plano Nacional de Educação e dá outras providências. Brasília, 2001a. Disponível em:

<http://www.planalto.gov.br/ccivil_03/leis/leis_2001/110172.htm>. Acesso em: 23 jul. 2016.

BRASIL. Conselho Nacional de Educação. Câmara de Educação Básica. Resolução CNE/CEB N ${ }^{o}$ 2, de 11 de setembro de 2001. Institui Diretrizes Nacionais para a 
Educação Especial na Educação Básica. Diário Oficial [da] República Federativa do Brasil, Brasília, DF, 14 set. 2001. Seção 1E, p. 39-40, 2001 b.

BRASIL. Conselho Nacional de Educação. Resolução CNE/CP 1/2002, de 18 de fevereiro de 2002. Institui Diretrizes Curriculares Nacionais para a Formação de Professores da Educação Básica, em nível superior, curso de licenciatura, de graduação plena Diário Oficial [da] República Federativa do Brasil, Brasília, DF, 9 abr. 2002. Seção 1, p. 31.

BRASIL. Resolução n⿳0 01/2003. Dispõe sobre os direitos dos profissionais da educação com formação de nível médio, na modalidade Normal, em relação à prerrogativa do exercício da docência, em vista do disposto na lei 9394/96, e dá outras providências. Disponível em: <http://portal.mec.gov.br/cne/arquivos/pdf/CEB01_2003.pdf〉. Acesso em: 30 set. 2016

BRASIL. Decreto $\mathrm{N}^{\mathbf{0}}$ 5.622, de 19 de dezembro de 2005. Regulamenta o art. 80 da Lei $\mathrm{n}^{\circ}$ 9.394, de 20 de dezembro de 1996, que estabelece as diretrizes e bases da educação nacional. 2005. Disponível em:

<http://portal.mec.gov.br/sesu/arquivos/pdf/portarias/dec5.622.pdf>. Acesso em: 27 maio 2016.

BRASIL. Resolução CNE/CP n⿳ 1/2006, de 15 de maio de 2006, que Institui Diretrizes Curriculares Nacionais para o Curso de Graduação em Pedagogia, Licenciatura. 2006. Disponível em:

<http://portal.mec.gov.br/cne/arquivos/pdf/rcp01_06.pdf〉. Acesso em: 21 maio 2016.

BRASIL. Ministério da Educação. O Plano de Desenvolvimento da Educação: razões, princípios e programas. 2007. Disponível em:

<http://portal.mec.gov.br/arquivos/livro/livro.pdf>. Acesso em: 26 maio 2016.

BRASIL. Política Nacional de Educação Especial na Perspectiva da Educação

Inclusiva. Brasília, DF, 2007. Disponível em:

<http://portal.mec.gov.br/seesp/arquivos/pdf/politica.pdf>. Acesso em: 23 jul. 2016.

BRASIL. Emenda Constitucional n 59, Presidência da República, Casa Civil,

Subchefia para assuntos jurídicos. Brasília, DF, 2009. Disponível em:

<http://www.planalto.gov.br/ccivil_03/constituicao/emendas/emc/emc59.htm>. Acesso em: 23 jul. 2016.

BRASIL. PNE 2011-2020: Metas e Estratégias 2010. Disponível em:

<http://fne.mec.gov.br/images/pdf/notas_tecnicas_pne_2011_2020.pdf>. Acesso em: 26 mai 2016.

BRASIL. Lei no 12.796, de 04 de abril de 2013. Presidência da República, Casa Civil, Subchefia para assuntos jurídicos. Brasília, DF, 2013. Disponível em: <http://www.planalto.gov.br/ccivil_03/_ato2011-2014/2013/lei/112796.htm>. Acesso em: 23 jul. 2016.

BRASIL. LEI No 13.005, de 25 de junho de 2014. Aprova o Plano Nacional de Educação - PNE e dá outras providências. 2014a

RIAEE - Revista Ibero-Americana de Estudos em Educação, Araraquara, v. 13, n. 1, p. 190-206, jan./mar., 2018. 
<http://www.planalto.gov.br/CCIVIL_03/_Ato2011-2014/2014/Lei/L13005.htm>. Acesso em: 26 maio 2016.

BRASIL. Plano Nacional de Educação. Observatório do PNE. Meta 15 - Formação de Professores. 2014b. Disponível em: <http://www.observatoriodopne.org.br/metaspne/15-formacao-professores>. Acesso em: 08 maio 2016.

BRASIL. Resolução CNE/CP 02/2015, de 01 de junho de 2015. Define as Diretrizes Curriculares Nacionais para a formação inicial em nível superior (cursos de licenciatura, cursos de formação pedagógica para graduados e cursos de segunda licenciatura) e para a formação continuada. 2015. Disponível em: <http://www.udesc.br/arquivos/id_submenu/83/res_cne_cp_002_03072015.pdf>. Acesso em: 27 maio 2016.

CARVALHO, R. E. A nova LDB e a Educação Especial. Rio de Janeiro: WVA, 1997.

DALL'ACQUA, M. J. C.; VITALIANO, C. R. Algumas reflexões sobre o processo de inclusão em nosso contexto educacional. In: VITALIANO, C. R. (Org.). Formação de professores para inclusão de alunos com necessidades educacionais especiais. Londrina: EDUEL, 2010. p.17-30.

DECLARAÇÃO Mundial de Educação para Todos, Jomtien-Tailândia, 1990. Conferência mundial sobre educação para todos: satisfação das necessidades básicas de aprendizagem. Jomtien-Tailândia, 5-9 de março de 1990. Disponível em: <http://www.unicef.org/brazil/pt/resources_10230.htm>. Acesso em: 30 set. 2016.

FERREIRA, J. R. A nova LDB e as necessidades educativas especiais. Cadernos CEDES, Campinas, v. 19 n. 46, set. 1998.

FERREIRA, W. B. 20 Anos depois de Salamanca: onde estamos e para onde vamos? Poíesis Pedagógica, Catalão-GO, v. 13, n. 1, p. 87-106, jan./jun. 2015.

GOMES, M. O. Formação de professores na educação infantil. São Paulo: Cortez, 2009.

MARÇAL, J. C. Progestão: como promover a construção coletiva do projeto pedagógico da escola? Módulo III. Brasília: CONSED - Conselho Nacional de Secretários de Educação, 2001.

MENDES, E. G. A radicalização do debate sobre inclusão escolar no Brasil. Revista Brasileira de Educação, Campinas, v. 11, p. 387-405, 2006.

MENDES, E. G. Inclusão Marco Zero: começando pelas creches. Araraquara, SP: Junqueira\&Marin, 2010.

MIZUKAMI, M. G. N. et al. Escola e aprendizagem da docência: processos de investigação e formação. São Carlos: EDUFSCar, 2002.

NÓVOA, A. Os professores e sua formação. Lisboa: Dom Quixote, 1995. 
RODRIGUES, D. Educação Inclusiva: dos conceitos às práticas de formação. Lisboa: Instituto Piaget, 2011.

SKRTIC, T. M. A injustiça institucionalizada: construção e uso da deficiência na escola. In: BUENO, J. G. S.; MUNAKATA, K.; CHIOZZINI, D. F. (Orgs.). A escola como objeto de estudo: escola, desigualdades, diversidades. Araraquara: Junqueira\&Marin, 2014. p. 173-210.

TARDIF, M. Saberes docentes e formação profissional. Petrópolis: Vozes, 2012.

\section{Como referenciar este artigo}

CARNEIRO, Relma Urel Carbone.; DALL'ACQUA, Maria Júlia Canazza.; CARAMORI, Patricia Moralis. Os 20 anos da Lei de Diretrizes e Bases e a Educação Especial: considerações e reflexões. Revista Ibero-Americana de Estudos em Educação, Araraquara, v. 13, n. 1, p. 190-206, jan./mar., 2018. E-ISSN: 1982-5587.

Submetido em: 20/08/2017

Revisões requeridas: $23 / 10 / 2017$

Aceito em: 20/12/2017 